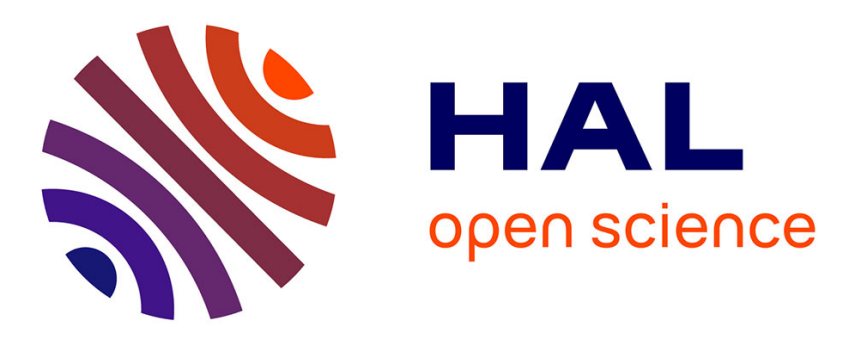

\title{
Enhanced anomalous diffusion of sputtered atoms in nanosized pores
}

\author{
Sujuan Wu, Pascal Brault, Cong Wang, Thierry Sauvage
}

\section{To cite this version:}

Sujuan Wu, Pascal Brault, Cong Wang, Thierry Sauvage. Enhanced anomalous diffusion of sputtered atoms in nanosized pores. Physica A: Statistical and Theoretical Physics, 2011, 390, pp.2112-2116. 10.1016/j.physa.2011.02.001 . hal-00581569

\section{HAL Id: hal-00581569 \\ https://hal.science/hal-00581569}

Submitted on 31 Mar 2011

HAL is a multi-disciplinary open access archive for the deposit and dissemination of scientific research documents, whether they are published or not. The documents may come from teaching and research institutions in France or abroad, or from public or private research centers.
L'archive ouverte pluridisciplinaire HAL, est destinée au dépôt et à la diffusion de documents scientifiques de niveau recherche, publiés ou non, émanant des établissements d'enseignement et de recherche français ou étrangers, des laboratoires publics ou privés. 


\title{
Enhanced anomalous diffusion of sputtered atoms in nanosized pores
}

\author{
Sujuan $\mathrm{Wu}^{\mathrm{a}, 1}$, Pascal Brault ${ }^{\mathrm{a}}$, Cong Wang ${ }^{\mathrm{b}}$, Thierry Sauvage \\ ${ }^{a}$ GREMI, UMR6606 CNRS-Université d'Orléans BP 6744, 45067 Orléans Cedex 2, \\ France \\ ${ }^{b}$ Center for Condensed Matter and Material Physics, Beihang University, Beijing, \\ 100191, China \\ ${ }^{c}$ CEMHTI, UPR3079 CNRS, 1D, av Recherche Scientifique, 45071 ORLEANS cedex 2, \\ France
}

\begin{abstract}
Plasma sputtering deposition of platinum catalysts in porous anodic aluminum oxide (AAO) templates is shown to generate an anomalous superdiffusion concentration profile. The growth of an overlayer between the hexagonal array of pores is shown to enhance the diffusion into the pores, leading to a diffusion coefficient having superlinear time dependence. The Pt clusters in the pores have a mean size of $10 \mathrm{~nm}$ and almost concentrate on the inner pore surface, and are present up to a depth of $6 \mu \mathrm{m}$.
\end{abstract}

Keywords: atom anomalous diffusion, cylindrical pore, atom transport, concentration profile

\section{Introduction}

Efficient development of highly functional porous materials, used as catalysts in the automotive, fuel cells, batteries, etc., is particularly welcome in reducing the losses of the precious metals and enhancing their catalytic efficiency [1, 2, 3]. The catalytic efficiency of these advanced porous materials strongly depends on the distribution of the nanoparticles, the concentration and size distribution in the porous media [3, 4, 5], hence these quantities

\footnotetext{
Email address: Pascal.Brault@univ-orleans.fr (Pascal Brault)

${ }^{1}$ present address: Center for Condensed Matter and Material Physics, Beihang University, Beijing, 100191, China
} 
must be predicted. Plasma sputtering deposition is known to provide a relevant way for designing catalytic thin films [1, 2, 6, 7, [8, 9]. The growth of the active layer is thus obtained by transport/diffusion/clustering steps of the sputtered atoms impinging the porous substrate. Usually, the diffusion in a porous medium is called anomalous and is characterized by the mean square displacement $\left\langle z^{2}(t)>\right.$ which evolves according to a power law in time $t^{\alpha}$ different from the well known linear behavior $(\alpha=1)$ for normal diffusion 10 . This anomalous diffusion can be observed in many domains such as transport in fractal media 11], solid surface diffusion [12] or hydrodynamics (rotating flows [13], turbulence [14] or diffusion in an array of convection rolls [15, 16]). Different models that involve space-dependent diffusion coefficients can be used to describe this anomalous diffusion process, [17, 18, 19, 20, 21]. In the present article, we study plasma sputtering platinum deposition on porous AAO templates by measuring the density profiles of the deposited matter at different times and compare them with concentration profiles issued from anomalous diffusion.

\section{Experiment}

Platinum is deposited by a radio frequency inductive plasma sputtering system which has been previously described [2, 3]. Briefly, an argon plasma is created in a 80 liter cylindrical stainless steel chamber by an external planar antenna powered by a $13.56 \mathrm{MHz}$ using a Radio Frequency generator at 100 $\mathrm{W}$ input power. AAO templates are placed on a rotating substrate holder in front of the sputtering target at a distance of $7.0 \mathrm{~cm}$. The Pt target is biased with a continuous DC potential $V_{b}=-100 \mathrm{~V}$ and the deposition time $t$ is in the range of $10 \mathrm{~min}$ to $50 \mathrm{~min}$ at argon pressure of $3.10^{-3} \mathrm{mbar}$. The morphology of the Pt coated AAO templates were analyzed by high resolution scanning electron microscopy (HRSEM, ZEISS). The platinum depth profiles were measured by Rutherford Backscattering Spectroscopy, with a Van de Graaf accelerator(CEMHTI-CNRS, Orléans, France) using a $2 \mathrm{MeV}{ }^{4} \mathrm{He}^{+}$ ion beam. The scattering geometry is : scattering angle $=165^{\circ}$, exit angle is $15^{\circ}$, incident angle is $0^{\circ}$. The detector size is $25 \mathrm{~mm}^{2}$ and sample to detector distance is $90 \mathrm{~mm}$.

\section{Results and discussion}

The AAO templates (purchased Pu-Yan Nanotechnologies, China) are made of cylindrical pores with average pore size of $90 \mathrm{~nm}$, a porosity of $25 \%$, 
and the density of the pore is $4.710^{9} \mathrm{~cm}^{-2}$. The pore are perpendicular to the external surface. The Pt deposited AAO templates have been observed by SEM (Fig. 1). The bright areas corresponds to the presence of platinum. The particle flux delivered by the plasma sputtering cannot be completly absorbed by the porous AAO template. Part of the Pt atoms is accumulated on the surface and part is deposited into the porous AAO and adsorbed on the inner walls as can be be shown in Fig. 1. As deposition time is increased from $10 \mathrm{~min}$ to $50 \mathrm{~min}$, the amount of Pt clusters staying on the surface is increased. In addition, Pt clusters on the channel inner surface can be observed (Fig. 1 d). The clusters have $10 \mathrm{~nm}$ size. Moreover EDS line-scan measurements (Fig. 2 along a pore cross- section confirms that Pt is significanltly incorporated inside the pores. To get more information about the depth concentration profiles of the Pt atoms in the porous AAO template, the samples are further investigated by RBS. A simulated spectrum is built using SIMNRA software [22] . it is obtained by considering a target made of successive layers with a given concentration of $\mathrm{Pt}$ and $\mathrm{Al}_{2} \mathrm{O}_{3}$. An iteration process is carried out until the simulated spectrum matches the experimental spectrum. The Pt depth concentration profiles are recovered when converting the $\mathrm{Al}_{2} \mathrm{O}_{3}$ concentration in a layers to an equivalent thickness interval, taking into account the porosity. Moreover, because the incident beam is perpendicular to the AAO surface, thus the Pt line shape mainly reflects the concentration profile, i.e. intensity at lower backscattered $\alpha$ particle energies do correspond to adsorbed $\mathrm{Pt}$ atoms on the pore wall. Because incident angle is $0^{\circ}$, a fraction of the incident beam is not scattered so the charge should be corrected by the fraction of pore area, i.e. $25 \%$.

Typical RBS spectra of Pt deposited AAO are shown in Fig. 3. The left side of the spectrum, at low backscattering energies, corresponds to $\mathrm{Al}, \mathrm{O}$ atoms, whereas on the right side, the asymmetrical peak originates from $\alpha$ particles backscattered by $\mathrm{Pt}$ atoms. The area under the Pt peak is directly related to the number of the platinum atoms in the porous substrate. The tail on the left side of the Pt peak indicates that atoms have penetrated into the porous substrate. This significant increase of the area under the peak and the extending of the tail reveal that the number of Pt atoms in the AAO templates is increasing and more Pt atoms are present in the channels as the sputtering time is increased. This is consistent with EDS measurements.

The depth density profiles (Fig. 4) of several successive Pt deposited AAO templates are obtained by fitting the experimental spectrum with a spectrum using a defined concentration profile. The best choice is given by 
the solution of anomalous diffusion [10, 17, 18, 19, 20] :

$$
\begin{array}{r}
\rho(z, t)=Z_{1}(t), \quad-z_{0}(t)<z \leq 0 \\
\rho(z, t)=Z_{1}(t) e^{-\frac{z^{2+\theta}}{Z_{2}(t)},} \quad z>0
\end{array}
$$

In Eq. 1, the depth profile is composed of a surface layer of height $z_{0}(t)$ and by a stretched gaussian concentration profile. $\theta$ is a dimensionless coefficient which characterizes the anomalous diffusion behaviour. If $\theta<0$ then the behaviour is superdiffusive else if $\theta>0$ it is subdiffusive. In our experiments, $\theta$ equals to $-\frac{5}{3} \pm 0.15$, which means that Ar plasma sputtered Pt atoms are subjected to superdiffusion in the cylindrical pores. More over, $Z_{1}(t)$ and $Z_{2}(t)$ exhibit power law dependence: $Z_{1}(t) \propto t^{0.75 \pm 0.05}$ and $Z_{2}(t) \propto t^{1.25 \pm 0.05}$. The maximum reached depth of $\mathrm{Pt}$ is increasing from $1.5 \mu \mathrm{m}$ to $6 \mu \mathrm{m}$ as the deposition time is increasing from $10 \mathrm{~min}$ to $50 \mathrm{~min}$. The density of the Pt atoms on the surface (overlayer) is increased when increasing deposition time. Figure 5 only displays a small depth range $(<400 \mathrm{~nm})$ for clarity.

We obtain an almost linear evolution of the total mass $\left(t^{1 . \pm 0.05}\right)$ of deposited platinum, as expected by the experimental process: the flux of $\mathrm{Pt}$ atoms impinging on the AAO template is constant. The mass of platinum inside the porous medium is found to scale as $t^{1.5 \pm 0.05}$, while the Pt mass of the surface overlayer scales as $t^{0.7 \pm 0.05}$ as shown on Fig. 5. The rate of nonlinear mass increase on the surface is smaller than rate of total mass one, while the rate of mass increase inside the pores is larger than the one of total mass. It indicates that part of the atoms deposited on the surface are gradually diffusing into the channels as deposition time is increasing, while part of the incoming flux is directly entering the pores i.e. with an amount corresponding to the ratio of the pores area to the total area. This growing external layer provides an additional source for the transport/diffusion of atoms inside the porous AAO and is dependent on the deposition time. In the process of deposition, $\mathrm{Pt}$ atoms arriving with a relatively high mean kinetic energy (around $7 \mathrm{eV}[3]$ ) and Ar ions from the plasma are also impinging the substrate [23, 24, 25]. So this superlinear process can be due to the flux of sputtered $\mathrm{Pt}$ atoms which do not only have collisions with AAO template, but also with the Pt atoms or Pt clusters deposited before and thus caused these Pt atoms to be driven into the channels. In addition, the surrounding plasma also has an interaction on these surface Pt atoms, mainly metastable atoms and ions that can cause another energy transfer [26, 27] 
favouring indiffusion when colliding with already deposited Pt atoms. Thus, the outer surface Pt atoms behave like an additional source for the diffusion of atoms inside the channels. Following ref. [21], we find a time dependant

diffusion coefficient $D(z, t)=D_{0} \frac{t^{\gamma}}{z^{\theta}}$ with $\gamma=\frac{1}{4}$ (see Appendix). This means that the diffusion is increased when increasing deposition time, i.e. when increasing the deposited mass. One can also notice, this behaviour is opposite to deposition into porous carbon [21] in similar conditions, for which mass inside porous layer is increasing slower than linearity. Because the porosity of the AAO is lower than in the porous carbon layer, we can invoke that the lower tortuosity of the AAO (the tortuosity of a random sphere packing is higher than for a cylindrical pore lattice) can be responsible for a superlinear inside mass increase.

\section{Conclusion}

During sputtering deposition, the diffusion of sputtered Pt atoms in the porous AAO substrate is found to be anomalous and it displays superdiffusion behaviour. Pt particles are not only deposited on the surface, part of them also diffuse into the porous substrate. This external growing layer provided an additional dynamical source for the diffusion of atoms inside the porous substrate and caused the increase of Pt mass inside the porous substrate in a superlinear way. The Pt particles with a mean size of $10 \mathrm{~nm}$ almost concentrate on the depth less than $400 \mathrm{~nm}$ and the reached maximum penetration depth increased to $6 \mu \mathrm{m}$ while the deposition time is increased to $50 \mathrm{~min}$.

\section{Acknowledgements}

Financial supports of the National Basic Research Program of China under grant number 2007CB613302 and from China Scolarship Council under grant number 2008602058 are gratefuly acknowledged. 


\section{Appendix}

In Ref. 21], scaling laws for anomalous diffusion equation with space and time dependent diffusion coefficient $D(z, t)=D_{0} \frac{z^{\theta}}{t^{\gamma}}$ are :

$$
\alpha=\frac{\gamma+1}{2+\theta} \quad \text { and } \quad \alpha+\beta=1+\epsilon
$$

with $\alpha$ and $\beta$ are issued from experiments considering that the concentration profile $\rho(z, t)$ can be considered as a self-similar solution of the anomalous diffusion equation, $\rho(z, t) \propto t^{\beta} f\left(\frac{z}{t^{\alpha}}\right)$ and that the experimental fitting functions are $\rho(z, t)=Z_{1}(t) e^{-\frac{z^{2+\theta}}{Z_{2}(t)}}$ with $Z_{1}(t) \propto t^{m}$ and $Z_{2}(t) \propto t^{p}$. So $\alpha=\frac{p}{2+\theta}$ and $\beta=m$. And thus parameters $\gamma$ and $\epsilon$ can be deduced using the set of equations (2).

\section{References}

[1] H. Rabat, C. Andreazza, P. Brault, A. Caillard, F. Beguin, C. Charles, R. Boswell, Carbon.47 (2009) 209.

[2] H. Rabat and P. Brault, Fuel Cells 8 (2008) 81.

[3] A. Caillard, P. Brault, J. Mathias, C. Charles, R. W. Boswell and T. Sauvage, Surf. Coat. Technol. 200, (2005) 391.

[4] O. Antoine, Y. Bultel, P. Ozil, R. Durand, Electrochim.Acta, 45 (2000) 4493.

[5] A. Caillard, C. Charles, R. Boswell, P. Brault, Ch. Coutanceau, Appl. Phys. Lett. 90 (2007) 223119

[6] M. Boutonnet-Kizling, S. G. Jaras . Appl Catal A: Gen 147 (1996)121.

[7] C. J. Liu, G. P. Vissokov, B.W. L. Lang, Catal Today 72(2002):17384.

[8] C. J. Liu, J. Zu , K. Yu , D. Cheng , Y. Han ,J. Zhan , C. Ratanatawanate, B. W. L. Lang, Pure Appl Chem 78 (2006)12271238. 
[9] A. Berthet, A. L. Thomann, F. J. Cadete Santos Aires, M. Brun, C. Deranlot, J.C. Bertolini, J.P. Rozenbaum, P. Brault and P. Andreazza, J. Catalysis 190 (2000) 4959.

[10] R. Metzler and J. Klafter, Phys. Rep. 339 (2000) 1.

[11] J. Stephenson, Physica A 222(1995) 234

[12] W.D. Luedtke and U. Landman, Phys. Rev. Lett. 82 (1999) 3835

[13] E.R. Weeks and H.L. Swinney, Phys. Rev. E 57 (1998) 4915

[14] L.F. Richardson, Proc. Roy. Soc. 110 (1926) 709

[15] O. Cardoso and P. Tabeling, Europhys. Lett. 7 (1988) 225

[16] W. Young, A. Pumir and Y. Pomeau, Phys. Fluids A 1,462 (1989).

[17] L. C. Malacarne, R. S. Mendes, I. T. Pedron and E. K.Lenzi, Phys. Rev. E 63 (2001) 030101(R)

[18] I. T. Pedron, R. S. Mendes, L.C. Malacarne and E. K.Lenzi , Phys. Rev. E 65 (2002) 041108

[19] C. Tsallis and E. K. Lenzi, Chem. Phys. 284, 341 (2002).

[20] B. O' Shaughnessy and I. Procaccia Phys. Rev. Lett. 54 (1985) 455.

[21] P. Brault, C. Josserand, J. Bauchire, A. Caillard, C. Charles, and R.W. Boswell, Phys. Rev. Lett. 102 (2009) 045901.

[22] Mayer M 1997 SIMNRA users guide, IPP 9/113 (Garching:MaxPlanck-Institut fur Plasma Physik) SIMNRA, homepage http://www.rzg.mpg.de/ mam

[23] A. L. Thomann, C. Charles, N. Cherradi, P. Brault, Plasma Sources Sci. Technol. 9 (2000) 176-182

[24] A. L. Thomann, C. Charles, P. Brault, C. Laure and R. Boswell, Plasma Sources Sci. Technol. 7 (1998) 245-251

[25] A. L. Thomann, P. Brault, C. Andreazza, P. Andreazza, H. Estrade, B. Rousseau, D. Babonneau, G. Blondiaux and J.P. Rozenbaum, J. Phys. D 30 (1997) 3197-3202 
[26] P. Brault, A. L. Thomann, C. Andreazza-Vignolle, Surf. Sci. 406, L597L602 (1998)

[27] A.-L. Thomann, J. P. Rozenbaum, P. Brault, C. Andreazza-Vignolle, P. Andreazza, Appl. Surf. Sci. 158, 172-183 (2000) 

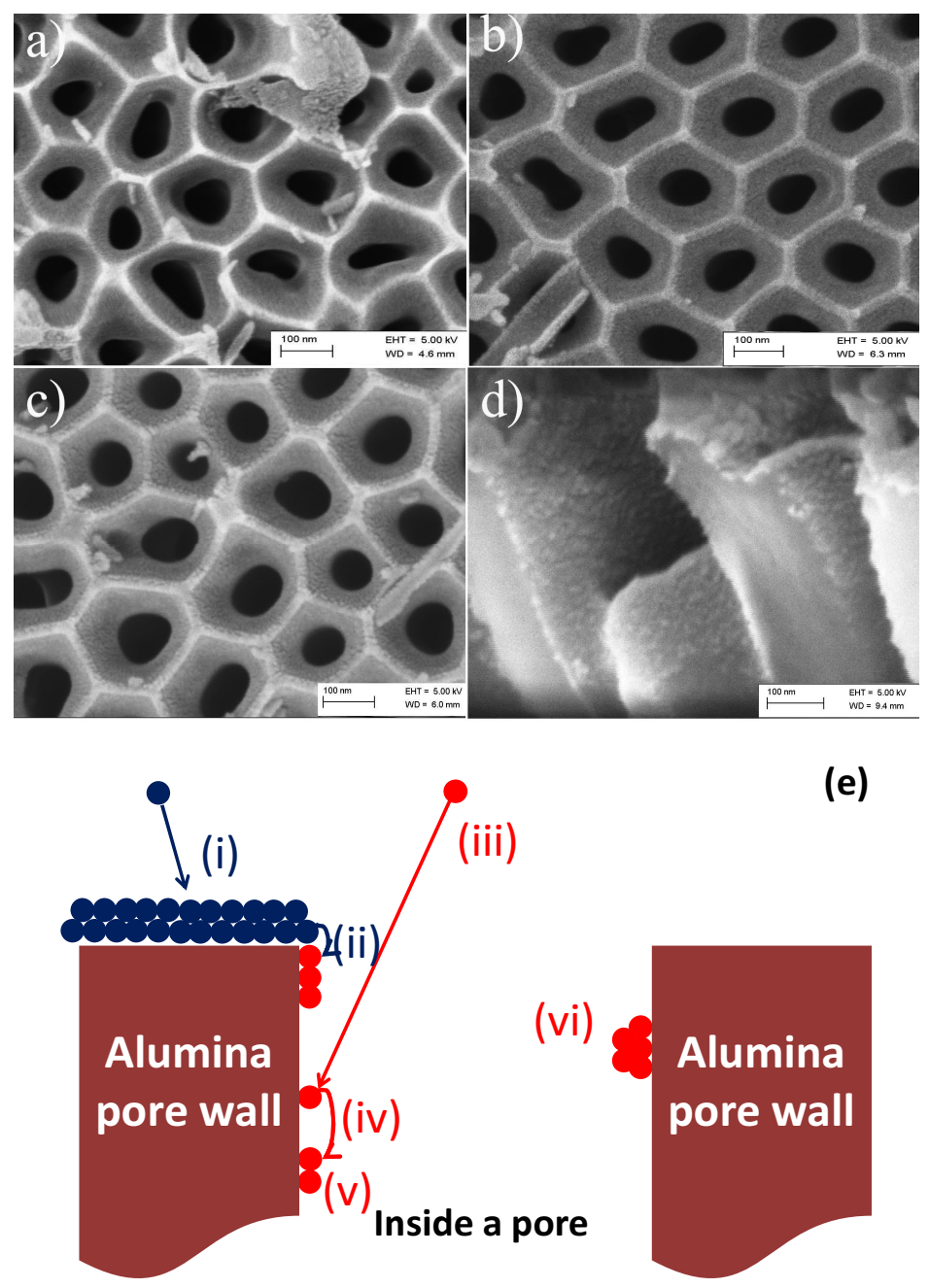

Figure 1: Scanning Electron Microscopy images of Pt deposited AAO template: a) $t=5$ min; b) $t=30 \mathrm{~min}$; c) $t=50 \mathrm{~min}$; d) Cross-section of Pt deposited $50 \mathrm{~min}$; e) Basic mechanism involved in the sputter deposition process i) deposition on the top surface separating pores ii) possible diffusion from top surface to inner pore surface iii)direct deposition into a pore iv) inner pore surface diffusion v) nucleation process in a pore vi)cluster growth inside a pore 


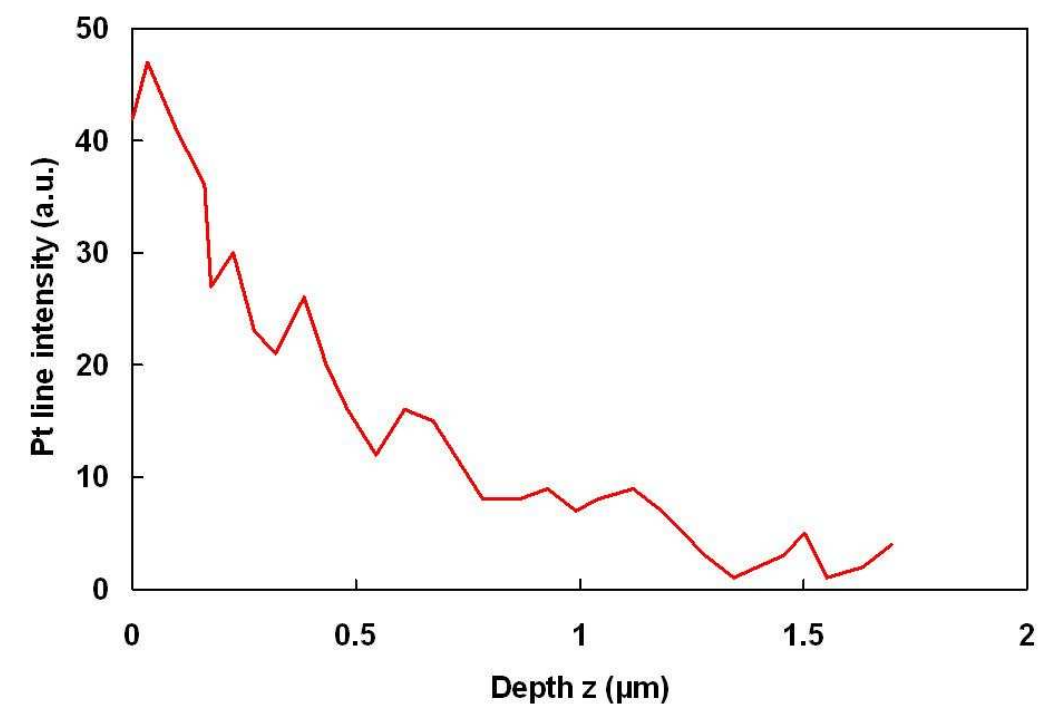

Figure 2: Typical Pt EDS line scan profile along a pore. $z=0$ is the outermost surface.

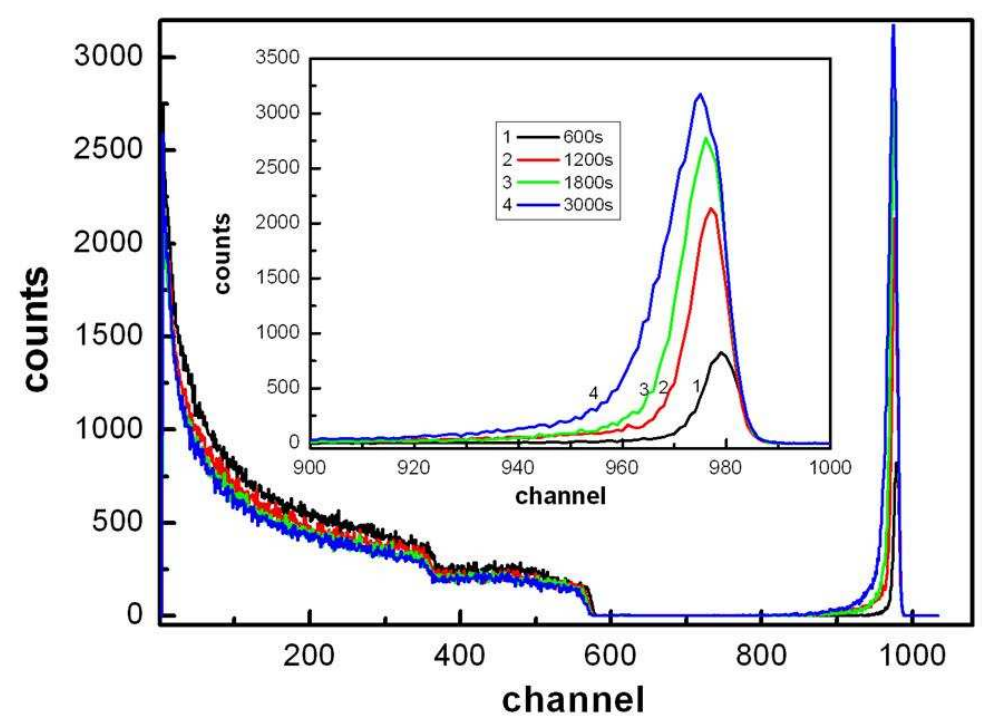

Figure 3: RBS spectra of different time Pt deposited AAO templates. 


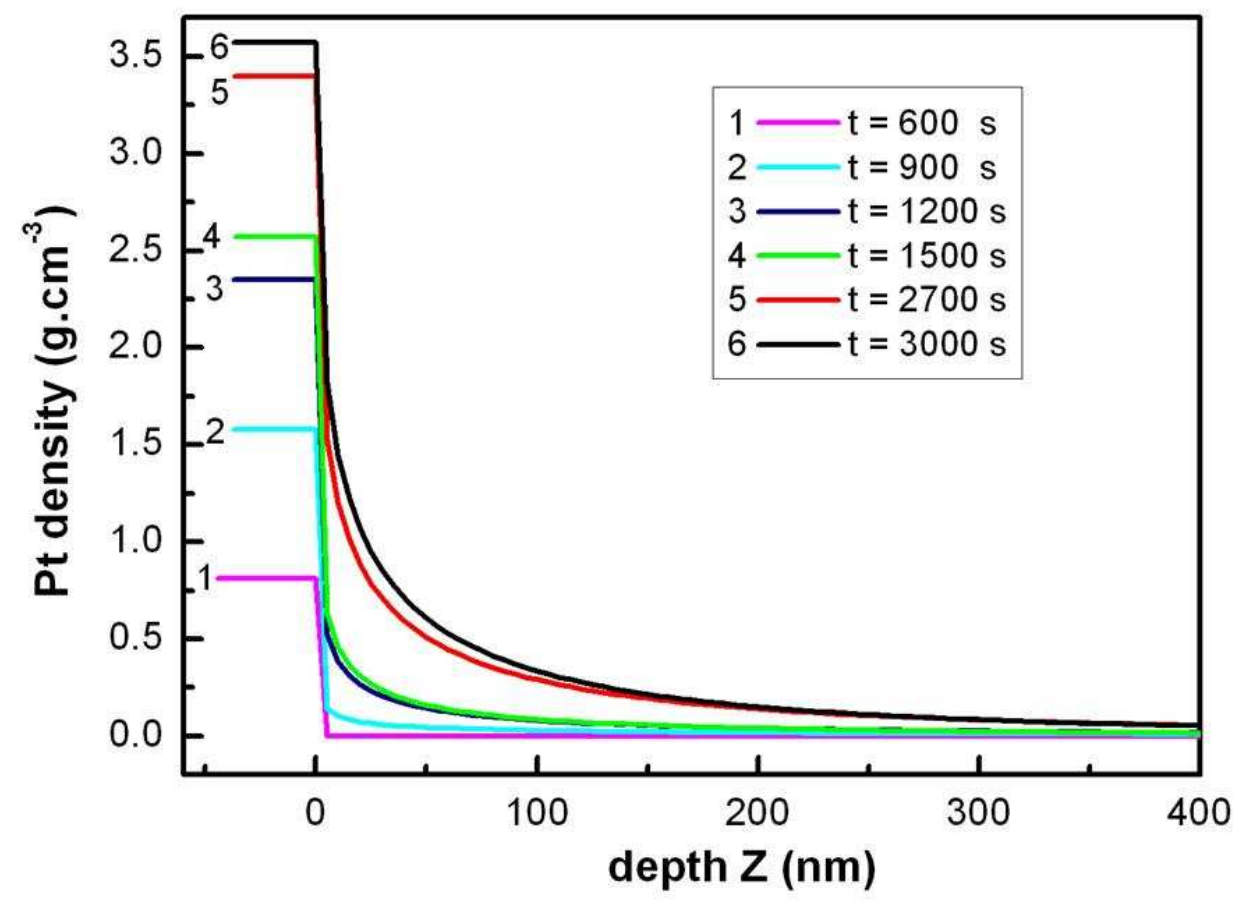

Figure 4: Pt depth density profiles in AAO template at different time in a range less than $400 \mathrm{~nm}$. 


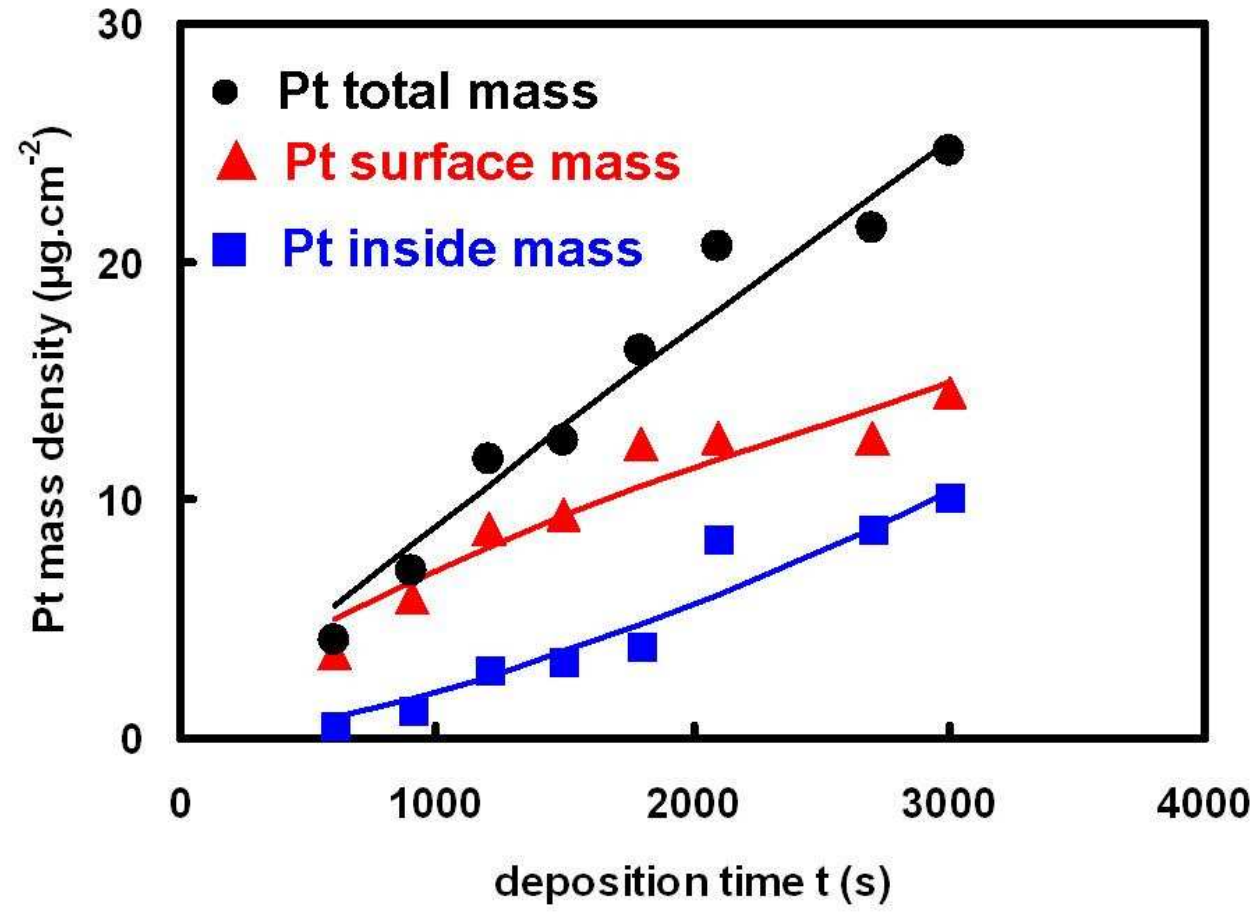

Figure 5: Time evolution of the surface, inside and total mass of deposited platinum. The lines are the power law fits. 